\title{
DIFICULDADES ENFRENTADAS PELOS PEQUENOS PRODUTORES NO DESEMPENHO DA ATIVIDADE PECUÁRIA LEITEIRA
}

\author{
Difficulties Faced by Small Producers in the Performance of the Dairy Livestock Activity
}

\begin{abstract}
RESUMO
O estudo teve como objetivo identificar as principais dificuldades enfrentadas pelo pequenos produtores de leite do município de Verê-PR. O delineamento da pesquisa é descritiva, por meio de levantamento, com abordagem qualitativa. O instrumento de coleta consiste em um questionário adaptado do estudo de Freitas (2014), sendo aplicado para vinte e cinco famílias de pequenos produtores. Os resultados mostraram que as principais dificuldades enfrentadas são: o preço do litro de leite, idade avançada, sucessão familiar, número reduzido de filhos e investimento em novas tecnologias. Pode-se identificar ainda que muitos produtores abandonam a pecuária leiteira devido a idade avançada, pois estão se aposentando e também, pela falta de mão de obra familiar para continuidade dos trabalhos da propriedade. Percebe-se uma redução no número de filhos e a migração dos jovens para a cidade em busca de emprego. Os produtores recebem auxílio de programas e ações voltados a produção de leite, porém relatam serem insuficientes para que consigam se manter em suas propriedades e citam a necessidade de implementação de políticas públicas que visem favorecer e fortalecer a atividade leiteira nas pequenas propriedades.
\end{abstract}

Camila Helfenstein

Universidade Tecnológica Federal do Paraná - UTFPR

camiis12@hotmail.com

Rafaela Pozenatto

Universidade Tecnológica Federal do Paraná - UTFPR

rafapozenatto@hotmail.com

Luciane Dagostini

Universidade Tecnológica Federal do Paraná - UTFPR

lu.dagostini2020@gmail.com

Nayane Thais Krespi Musial

Universidade Federal do Paraná - UFPR

nkrespi@gmail.com

Recebido em: 01/05/2020. Aprovado em: 04/03/2021.

Avaliado pelo sistema double blind review

Avaliador científico: Eduardo César Silva

DOI: $10.48142 / 2320211647$

\begin{abstract}
The study aimed to identify the main difficulties faced by small milk producers in the municipality of Verê - PR. The research design is descriptive, by means of a survey, with a qualitative approach. The collection instrument consists of a questionnaire adapted from the study by Freitas (2014), being applied to twenty-five families of small producers. The results showed that the main difficulties faced are the price of a liter of milk, old age, family succession, reduced number of children and investment in new technologies. It can also be identified that many producers abandon dairy farming due to old age, as they are retiring and, due to the lack of family labor to continue the work on the property. There is a reduction in the number of children and the migration of young people to the city in search of jobs. Farmers receive assistance from programs and actions aimed at milk production, but they report that they are insufficient for them to be able to stay on their properties and cite the need to implement public policies aimed at favoring and strengthening dairy activity on small farms.
\end{abstract}

Palavras-chave: Leite; Pequenas propriedades; Políticas públicas.

Keywords: Milk; Small farms; Public policy.

\section{INTRODUÇÃO}

O leite e seus derivados são consumidos por mais de 6 bilhões de pessoas em todo o mundo, a maior parte residente em países em desenvolvimento, com consumo per capita dobrado desde o início da década de 1960. Entretanto, o crescimento do consumo é considerado lento, quando comparado ao de outros produtos de origem animal, como a carne que triplicou e os ovos que quintuplicaram, no mesmo período de tempo (FAO, 2021). Considerando que o leite é uma importante fonte de alimento, com relevância econômica, também representa uma atividade importante de produção para diferentes tipos de propriedades e mercados (Carvalho, 2013; Júnior \& Jung, 2017). 
O Brasil é o quarto país com maior produção de leite no mundo, além de representar uma atividade econômica relevante, com uma importante função social na geração empregos e no desenvolvimento regional (Zoccal, 2017; Bánkuti, Damasceno, Schiavi, Kuwaraha, \& Prizon, 2018). A atividade de pecuária leiteira é desenvolvida por muitos produtores rurais, no mundo todo, sob diferentes sistemas de produção e em propriedades de grande, médio ou pequeno porte (de Souza Costa, de Albuquerque Assunção, Costa, \& Chacon, 2015). No Brasil, destaca-se, sobretudo, o sistema de produção leiteira da agricultura familiar, predominante na região Sul (Júnior \& Jung, 2017) onde as pequenas propriedades são responsáveis pela produção de 58\% do leite consumido no Brasil (Instituto Brasileiro de Geografia e Estatística [IBGE], 2009) e cerca de 47\% da produção de leite nacional (Zoccal, 2017).

Além deste papel de fonte de renda dos pequenos produtores, o processo de produção do leite tem se aprimorado, ao longo do tempo, refletindo em mudanças relacionadas a toda a sua cadeia produtiva, fato que se deve a novos estudos e a pesquisas que promoveram avanços nos modos de produção, no manejo do gado e no melhoramento genético, contribuindo para que o setor seja uma atividade com excelentes perspectivas de viabilidade econômica, independentemente, do tamanho da propriedade rural em que é desenvolvida (Porto, 2017).

Entretanto, não basta apenas haver melhorias no processo produtivo, é necessário que hajam políticas públicas que deem suporte para o desenvolvimento sustentável da atividade. Uma vez que elas são implementadas por meio de ações e programas que podem auxiliar os pequenos produtores de leite no desenvolvimento de todo o processo produtivo com qualidade (Telles, Tanaka, \& Pellini, 2008; Freitas, 2014).

Assim, as políticas públicas por parte das instituições, entidades ou órgãos públicos tornam-se importante para incentivar os trabalhadores familiares envolvidos no desempenho de atividades desenvolvidas nas pequenas propriedades (Grisa \& Schneider, 2014). Pois, elas são primordiais para facilitar a adequação das propriedades familiares produtoras de leite ao ambiente institucional e de mercado, considerando que as vulnerabilidades podem ser minimzadas mediante arranjos coletivos (Cruz, 2012; Mendonça et al., 2020).

Levando-se em consideração que, em muitas regiões, a cadeia produtiva leiteira é composta principalmente por pequenos produtores, com pouca competitividade, infraestrutura e contando principalmente com mão de obra familiar (de Sousa Costa et al., 2015), o que dificulta a continuidade da atividade e que motiva muitos produtores a interrompê-la (Freitas, 2014), devido à escassez de recursos para investir nas melhorias e pela falta de conhecimento sobre programas de incentivos públicos oferecidos (Porto, 2017). Vale pontuar que a descontinuidade da atividade leiteira reflete em mudanças na estrutura agrária, no contexto de produtores e trabalhadores e, desta forma, afeta a estrutura socioeconômica regional (Craviotti \& Vértiz, 2020).

Neste sentido, as políticas públicas viabilizam a agricultura familiar, promovendo e fortalecendo seu desenvolvimento (Telles et al., 2008). Corroboram ArendsKuenning, Kamei, Garcias, Romani e Shikida (2020) ao evidenciarem que o fornecimento de crédito subsidiado por programas do Governo, como o Pronaf - Programa Nacional de Fortalecimento da Agricultura Familiar, que incentiva as famílias a fazer planos de sucessão familiar, tão logo a permanência na atividade rural.

Ainda, devem ser considerados outros fatores quando se trata da continuidade e dificuldades no desenvolvimento da atividade leiteira em pequenas propriedades. Tais como o envelhecimento da população, redução do tamanho das famílias, aumento do nível de escolaridade mediante oportunidades educacionais, o que leva a busca por outras atividades fora da propriedade, preços de venda praticados e qualidade do rebanho (Freitas, 2014; Bánkuti et al., 2018; Arends-Kuenning et al., 2020; Craviotti \& Vértiz, 2020).

Diante deste contexto, destaca-se a problemática da pesquisa: quais as principais dificuldades enfrentadas pelos pequenos produtores de leite do município de Verê - PR? Por conseguinte, o objetivo da pesquisa consiste em identificar as principais dificuldades enfrentadas pelos pequenos produtores de leite do município de Verê - PR. Com o intuito de levantar o perfil socioeconômico dos pequenos produtores de leite, suas dificuldades no desenvolvimento da atividade de pecuária leiteira, bem como as políticas públicas disponíveis para fortalecer o desenvolvimento local e regional da atividade.

Segundo Freitas (2014, pp. 10-11) "a produção de leite com origem em estabelecimentos de agricultura familiar é maior que a produzida nos estabelecimentos não familiares". Levando em consideração a representatividade da produção leiteira como fonte de renda para as famílias residentes na zona rural, e também sua contribuição para o desenvolvimento econômico de diversas regiões, este estudo se torna interessante para a identificação dos desafios enfrentados pelos pequenos produtores, tendo 
como objeto de estudo as propriedades rurais situadas no município de Verê - PR.

Diante disso e frente às dificuldades de permanência na atividade, relacionadas, principalmente, com as mudanças tecnológicas, as variações de preços pagos aos produtores pelo produto, na aquisição de insumos para manter a produção, afetam a continuidade e a melhoria de toda a estrutura que a permeia.

A pesquisa buscou evidenciar os pequenos produtores de leite e as principais dificuldades enfrentadas na produção. Também trará contribuições para outras pesquisas com resultados práticos e reais vivenciados pela amostra da pesquisa, incentivando e somando a outras pesquisas da área, o que possibilitará suprimentos aos órgãos responsáveis do município para a elaboração de novos projetos que visem a solucionar os problemas e dificuldade relatados pelos pequenos produtores de leite.

\section{REFERENCIAL TEÓRICO}

Nesta seção são apresentados os aspectos relacionados à atividade de pecuária leiteira no cenário nacional, regional e estadual, bem como a apresentação de políticas públicas e de estudos correlatos à pesquisa.

\subsection{Atividade pecuária leiteira no Brasil}

O leite é um produto essencial para a alimentação humana, pois apresenta nutrientes importantes para a saúde sendo caracterizado como um dos principais produtos do segmento da agropecuária, pois, por meio deste, podem ser obtidos vários derivados e com diferentes preços de comercialização, apresentando um papel significativo para a economia e para a subsistência de muitas famílias (Porto, 2017). Corroboram, neste sentido, de Sousa Costa et al. (2015) e Júnior e Jung (2017), ao afirmarem que a produção de leite e seus derivados refletem na geração de empregos em decorrência da quantidade de mão de obra dispendida em todo o processo.

A atividade leiteira se faz importante na geração de recursos públicos por meio do recolhimento de tributos além de ser desenvolvida em várias regiões do território brasileiro, valendo-se de diferentes sistemas de produção e em propriedades de tamanho variado, grande, médio ou pequeno porte. Sua produção, de certa forma, compõe a renda dos agricultores de todo o país, possibilitando o desenvolvimento da região em que se encontra, gerando crescimento individual e coletivo (Telles et al., 2008; de Sousa Costa et al., 2015).
As regiões que se destacam na produção leiteira, no Brasil, são: a região Sudeste, com ênfase o estado de Minas Gerais, sendo este o maior produtor do Brasil; a região Sul, com ênfase os estados de Rio Grande do Sul e Paraná; e, a região Centro-Oeste com destaque ao estado de Goiás. Ou seja, a atividade leiteira está presente na economia de quase todos os estados brasileiros (Zoccal, 2017).

Quase metade do leite produzido no país, cerca de $47 \%$ do total, é proveniente de pequenas propriedades. "Para 1,2 milhão de produtores o leite é o salário do mês. Leite é a atividade que mais gera empregos no País, mais de 4 milhões de pessoas trabalham nas indústrias de laticínios e no campo com a produção primária” (Zoccal, 2017, p. 1).

A produção brasileira, em 2014, foi de 35,2 bilhões de litros, representando aumento de $2,7 \%$ em relação ao ano de 2013. Em virtude disso, o Brasil conquistou a quinta posição na produção de leite no ranking mundial, ficando atrás de algumas grandes potências econômicas mundiais como: União Europeia, Índia, Estados Unidos e China (IBGE, 2015).

Segundo o Ministério da Agricultura, Pecuária e Abastecimento - MAPA (2015), “a produção de leite deverá crescer a uma taxa anual entre $2,4 \%$ e 3,3\%. Essas taxas correspondem a produção de 37,2 bilhões de litros em 2015, para valores entre 47,5 e 52,7 bilhões de litros no final de 2025". Percebe-se que a produção leitera possui perspectivas de crescimento contante com o passar dos anos. Consoante a isto, o consumo do produto também demonstra uma estimativa de crescimento significativo durante o mesmo período a uma taxa de 2,4\% ao ano (MAPA, 2015).

Em relação à estimativa de crescimento da produção de leite, no Brasil, Freitas (2014, p. 7) destaca que " o segmento é forte para a economia e que melhoras vêm acontecendo no setor, facilitando os investimentos nos estabelecimentos que trabalham com essa proteína, o que pode tornar o leite uma das principais potências econômicas do Brasil". Em 2016, o faturamento com essa atividade chegou a R 27 bilhões para a economia do país. Proveniente da modernização e da introdução de novas tecnologias, a produção leiteira teve mudanças significativas fazendo com que o desempenho da atividade seja, cada vez, melhor.

Zoccal (2017, p.1) enfatiza que "evoluções tecnológicas e de gestão estão acontecendo de forma silenciosa na atividade leiteira". Ainda, contribui que "o leite caminha para uma pecuária inteligente, em que a disponibilidade de tecnologias é cada vez mais forte, por exemplo, a biotecnologia, os veículos autônomos, como os tratores, drones, robôs e os sensores". 
Neste contexto, a atividade deixa de ser totalmente desenvolvida de forma manual, abrindo espaço para que as novas tecnologias venham contribuir para melhorar o processo produtivo e a qualidade do produto final entregue pelo produtor. Em contrapartida, seu crescimento e, principalmente, o surgimento de novas tecnologias na área (melhoria na genética do rebanho, novos equipamentos) precisam ser analisados cuidadosamente pelos produtores, pois podem trazer benefícios ou dificuldades, ao serem introduzidas nas propriedades, principalmente nas de pequeno e médio porte, que podem ser beneficiadas pela redução da necessidade de mão de obra e, em contrapartida, por não possuírem acesso aos recursos financeiros e capacidade operacional (Porto, 2017; Zoccal, 2017).

\subsection{Pecuária leiteira na região Sul do Brasil}

A região Sul do Brasil é formada por três estados: Paraná, Santa Catarina e Rio Grande do Sul, cuja capacidade de produção de leite é significativa à economia nacional e de destaque dentre as demais regiões do país (Zoccal, 2017). A região Sul ocupa a primeira posição do ranking em produção leiteira das Grandes Regiões, desde 2014, quando ultrapassou pela primeira vez a Região Sudeste (IBGE, 2015). Com base nos dados do IBGE (2015), "o Rio Grande do Sul obteve o melhor indicador (3073 litros/vaca/ano), seguido por Paraná (2840 litros/vaca/ano) e Santa Catarina (2755 litros/vaca/ano)".

Os três estados juntos lideram a produção nacional de leite. De acordo com o IBGE, em 2015, a região Sul foi responsável por $35,2 \%$ dos 35 bilhões de litros de leite produzidos no Brasil sendo que os estados do Paraná e Rio Grande do Sul juntos, representam 75,2\% da produção regional e 26,5\% da produção de leite do País. Dados da Secretaria de Estado da Agricultura -SEAB e do Departamento de Economia Rural - DERAL (2017, p. 4) apontam que "os três estados do Sul produziram 12,3 bilhões de litros. Produção superior à da Argentina, país tradicional na produção leiteira e que em 2015 produziu 11,314 bilhões de litros".

O desenvolvimento da cadeia produtiva em conjunto dos três estados se deve em virtude de apresentarem características similares no processo produtivo, fazendo com que a região prospere junto ao crescimento pecuário leiteiro. "A expectativa é de aumento na produção leiteira nos próximos 10 anos nos três estados, alcançando os 19,5 milhões de toneladas de litros por ano, $77 \%$ a mais do que é produzido hoje" (SEAB/DERAL, 2017, p. 4).
A produção leiteira da região apresenta fatores que estão interligados na explicação das diferenças dessa atividade em comparação com outras regiões do país. Talvez, o mais importante fator de sucesso seja que a gestão do negócio na região Sul, tende a ser pautada na inovação tecnológica e não apenas nas questões climáticas. Vale ressaltar que a produção leiteira representa a maior densidade de produção de leite por área territorial, com reduzido custo de captação e favorecimento no desenvolvimento da atividade industrial, apresentando importante papel na produtividade em contexto nacional (Carvalho, Oliveira \& Beskow, 2017).

\subsection{Pecuária leiteira no Paraná}

O Paraná foi considerado, pelo segundo ano consecutivo, o segundo maior produtor de leite do país (IBGE, 2017). No período 2008 - 2012, o aumento médio da produção brasileira de leite foi de $17 \%$, enquanto o crescimento da produção paranaense foi de $40 \%$, sendo considerado o percentual de aumento mais elevado do país. A SEAB/DERAL (2017) destaca que o estado do Paraná ocupa o segundo lugar no ranking de produção leiteira, com 4,66 bilhões de litros produzidos, sendo precedido pelo estado de Minas Gerais, com produção de 9,1 bilhões de litros, o que corresponde a $26,6 \%$ de toda a produção nacional.

Neste contexto, o secretário de Estado da Agricultura e do Abastecimento, Norberto Ortigara, afirmou em entrevista à Agência de Notícias do Paraná (2016), que, para se chegar a resultados expressivos, em relação à produção de leite, existem vários fatores envolvidos. Dentre eles, a Bacia Leiteira do Sudoeste do Paraná se tornou a maior do estado em produção, por meio de auxílios, programas e incentivos do próprio governo visto que, para muitas famílias, a atividade se tornou alternativa de renda devido ao tamanho ideal de suas propriedades.

Ainda, para a Agência de Notícias do Paraná (2016), há destaque para a região Sudoeste do Paraná, composta por 42 municípios, com predominância de pequenos produtores, que buscam na atividade leiteira oportunidades para geração de renda, produzindo cerca de 1 bilhão e 200 milhões de litros por ano.

Neste cenário, muitas famílias acabam se envolvendo na produção do leite, por ser uma atividade com renda mensal, de ter a viabilidade de ser desenvolvida na pequena propriedade e promove a inserção de mão de obra familiar (Porto, 2017). Neste sentido, corroboram Júnior e Jung (2017), ao mencionarem que 
esta atividade consolida-se na região Sul como familiar, sendo considerada como a âncora dos rendimentos dos pequenos agricultores, refletindo economicamente no desenvolvimento regional.

Em se tratando da atividade leiteira relacionada ao local de estudo, o município do Verê - PR, conta com um rebanho de bovinos de 20.021 cabeças, sendo que desta quantidade 9.009 são de vacas ordenhadas, distribuídas nas propriedade rurais em todo o município. Representando uma quantidade produzida de leite de 42.224.000,00 milhões de litros no ano de 2017, promovendo uma receita de $\mathrm{R} \$ 49.003 .000,00$ milhões no ano (IBGE, 2017). Levando em consideração que a comercialização do leite reflete na economia local e, consequentemente, na geração de tributos, que acabam sendo revertidos em forma de benefícios oferecidos para a toda a população local.

\subsection{Políticas públicas à agricultura familiar em Verê - PR}

O processo de desenvolvimento rural possuí implicações inerentes à formulação de políticas públicas relacionadas à agricultura familiar. Apesar da diversificação das políticas públicas, suas ações são voltadas ao acesso a terra, crédito, moradia rural, comercialização de produtos (Vargas, Ferreira, Godoy, \& Guedes, 2017). Neste sentido, foram apurados alguns projetos, programas e ações implementados pela Prefeitura Municipal do município de Verê - PR.

Programa Saúde Animal: Disponibilizado pela Prefeitura Municipal de Verê, com o objetivo de beneficiar os produtores de leite pertencentes ao município. A administração municipal, por meio do Departamento Municipal de Agricultura e Meio Ambiente, criou o Programa "Saúde Animal", colocou à disposição dos produtores de leite dois veterinários do município gratuitamente, que se deslocam até as propriedades rurais para realizar o acompanhamento clínico dos rebanhos e repassar conhecimento técnico. Desta forma, esse programa auxilia na produção para o desenvolvimento da atividade leiteira, refletindo na lucratividade obtida.

Programa Melhoramento Genético em Bovinos: Disponibilizado pela Prefeitura Municipal de Verê - PR. Este programa tem como objetivo difundir a inseminação artificial com técnicas simples e de fácil acesso. Prestando serviço de qualidade aos produtores do município e o melhoramento genético do rebanho de leite, elevando os índices de produtividade na propriedade.
O Departamento Municipal de Agricultura e Meio Ambiente, responsável pelo desenvolvimento deste programa, atende aos produtores de gado leiteiro que possuem botijões para inseminação artificial com nitrogênio líquido. O produtor rural, proprietário de botijão de conservação de sêmen ou terceirizado, receberá do Município incentivo financeiro de $50 \%$ do seu custo de manutenção. Os beneficiados terão apoio técnico da Secretaria Municipal, por meio de médico veterinário e técnico agrícola para averiguação do serviço prestado e resultados obtidos.

Curso de Capacitação sobre Vacas Leiteiras: Disponibilizado pela Prefeitura Municipal de Verê - PR, por meio da Secretaria Municipal de Agricultura, em parceria com o SENAR, esta ação tem como objetivo que os produtores aprendam a avaliar as vacas e identificar qual seria o animal ideal para a produção de leite e reprodução de bezerros. Desta forma, quando forem comprar sêmen, eles saberão avaliar os touros disponíveis e as características para que consigam o melhoramento genético que precisam.

Leite Sudoeste: O Programa Leite Sudoeste é coordenado pela Amsop - Associação dos Municípios do Sudoeste do Paraná, com apoio de entidades ligadas à agricultura, como Emater, Seab, Senar e Secretaria Especial de Agricultura Familiar e Desenvolvimento Agrário do Governo Federal. O objetivo é capacitar técnicos das prefeituras para que estes levem aos agricultores informações referentes à gestão de propriedades e procedimentos que melhorem o desempenho da atividade.

Obra de Cascalhamento: Disponibilizado pela Prefeitura Municipal de Verê - PR, por meio da Secretaria Municipal de Viação, Obras e Serviços Públicos. Foram realizadas no município obras de cascalhamento nas estradas que davam acesso às estrabarias dos produtores de leite, visando melhorar o acesso, pois, em dias mais chuvosos dificultava o trabalho do produtor.

Atualmente, cerca de 1,3 milhões de estabelecimentos da agricultura familiar estão voltados para a produção de leite e derivados. Dentre as políticas públicas do Ministério do Desenvolvimento Agrária MDA para o setor, são destaque o Programa Nacional de Fortalecimento da Agricultura Familiar - Pronaf, por meio do crédito rural e o Programa de Garantia de Preços para a Agricultura Familiar - PGPAF (Bianchini, 2015).

Uma das características do produtor de leite da agricultura familiar é a de investir, com frequência, no seu negócio, seja ampliando instalações e rebanho, ou melhorando as pastagens. Com o PGPAF, que concede 
desconto para o pagamento de financiamentos de custeio e investimento, o valor é abatido quando o produto financiado no mercado está abaixo do preço de garantia (Kuhn \& Junior, 2015). Já o Pronaf, que foi criado em 1995 pelo Governo Federal, tem como objetivo prestar um atendimento diferenciado aos pequenos agricultores, cuja produção é resultado de sua própria força de trabalho ou da mão de obra familiar.

Dado que o intuito deste programa é o fortalecimento das atividades desenvolvidas pelo pequeno agricultor, integrando-o à cadeia do agronegócio por meio da modernização do sistema produtivo. Desta forma, seu produto passa a contar com um valor agregado, o que, no final, proporcionará um aumento de renda a esse produtor. O programa conta com as menores taxas de juros para financiamento rural do mercado (Kuhn \& Junior, 2015).

Tendo em vista os aspectos analisados, também é importante frisar que a filiação dos produtores de leite em cooperativas, sindicatos e associações fortalece o setor, ajudando na melhoria do desempenho da atividade (Carvalho, 2013). Na sequência, são abordadas pesquisas alinhadas com os objetivos propostos neste estudo.

\subsection{Estudos correlatos}

Nesta seção são apresentados os estudos correlatos à pesquisa, no intuito de dar suporte à temática abordada bem como propiciar o cotejamento com os resultados obtidos. Neste contexto, abordam-se pesquisas relacionadas à atividade leiteira voltada para a agricultura familiar e políticas públicas.

Telles et al. (2008) analisaram a efetividade de políticas públicas paranaenses recentes ligadas à pecuária leiteira no sentido de apoiar a agricultura familiar, tendo como base o programa estadual Leite das Crianças. Apontando a viabilidade da agricultura familiar com ênfase na necessidade de políticas públicas que garantam a representação deste segmento, promovam o desenvolvimento, gerando empregos e reduzindo assim a pobreza no campo. Destacando que as políticas públicas são importantes para a manutenção das pequenas propriedades.

Também Parré, Bánkuti e Zanmaria (2011) realizaram uma pesquisa com 202 produtores de leite da região Sudoeste do Paraná com o intuito de caracterizar produtores de leite da região Sudoeste do Paraná. Os resultados indicaram que o sistema leiteiro da região Sudoeste é organizado e que maiores níveis de produtividade podem estar relacionados a fatores como: nível tecnológico, uso de mecanismos de gestão, tempo na atividade leiteira, tamanho de área e acesso a recursos, capacitação e assistência técnica, entre outros. Também, que possíveis melhorias podem estar associadas a programas de acesso ao crédito para investimentos e melhorias, programas de assistência técnica, entre outros.

Em pesquisa realizada por Freitas (2014), que buscou analisar os principais desafios enfrentados pelos produtores de leite da linha 3, no município de Cacoal-RO, por meio de aplicação de questionário para 12 produtores de leite de duas associações, os resultados apontaram como principais dificuldades o preço de venda do leite, falta acesso às políticas públicas e rebanho com baixa qualidade genética. Além de que, devido à pouca disponibilidade de mão de obra, idade avançada e redução do tamanho das famílias, muitos produtores estão parando de trabalhar com a pecuária leiteira.

O estudo de Grisa e Schneider (2014) apresentou uma análise a trajetória de construção de políticas públicas para a agricultura familiar no Brasil, pautada em três gerações ou referenciais de políticas públicas para a agricultura familiar, sendo: (i) fortalecimento do viés agrícola e agrário da categoria social; (ii) políticas sociais e assistenciais e; (iii) construção de mercados orientados pela segurança alimentar e pela sustentabilidade ambiental. Destacam que a sociedade civil passou a ser mais propositiva, ao invés de adotar postura crítica e reivindicativa. Entretanto, evidenciam que as políticas públicas em muito contribuem para o desenvolvimento agrário e social.

Da mesma forma que, Loose et al. (2019) investigaram as dificuldades enfrentadas pela agricultura familiar em uma região do Brasil, sendo o munícipio de Cacoal-RO, apontando dificuldades com acesso ao crédito, preços praticados, dificuldades de malha viária para escoamento da produção e falta de assistência técnica especializada. Fatos estes que carecem de políticas públicas para valorização da atividade.

Breitenbach e Rosolen (2020) fizeram um estudo utilizando a ferramenta Fofa - forças, fraquezas, oportunidades e ameaças, para uma análise estratégica do setor produtivo de leite no Rio Grande do Sul. Tendo como resultados: (i) forças - flexibilidade dos sistemas produtivos de leite, mão de obra familiar, garantia de renda mensal, possibilidades de comercialização e a agroindustrialização; (ii) fraquezas - mão de obra pouco qualificada, dificuldades para implantar tecnologias, margem de lucro baixa e dificuldades de sucessão familiar; (iii) oportunidades - políticas agrícolas, crescimento de demanda e assistência técnica qualificada e; (iv) ameaças 
- instabilidade de preços e custos, a escassez de políticas para o setor e concorrência com outros países.

Arends-Kuenning et al. (2020) examinaram as decisões de sucessão de fazendas de pequenos produtores no Oeste do Paraná. Concluíram que Programas do governo que fornecem crédito subsidiado e incentivam as famílias a fazer planos de sucessão e podem aumentar as taxas de sucessão. O envelhecimento da população junto ao declínio da fertilidade e oportunidades educacionais ampliadas para os jovens, apresentam desafios para a continuação da agricultura familiar ao longo das gerações.

No que tangem às dificuldades e aos cenários da atividade leiteira em pequenas propriedades sem abordagem de políticas públicas, de Sousa Costa et al. (2015) analisaram os custos da cadeia de valor dos laticínios de pequenos produtores de leite da região do Seridó, no estado do Rio Grande do Norte no ano de 2012 evidenciando que os produtores precisam obter mais conhecimentos por meio de novas experiências que proporcionem alternativas mais eficazes e viáveis para o processo produtivo.

Bánkuti et al. (2018) discutiram as condições de trabalho, sucessão familiar e características estruturais da atividade leiteira paranaense elucidando que é uma atividade que emprega uma quantidade grande de pessoas e é propulsora do desenvolvimento regional. Entretanto, como desvantagens são apontadas as más condições de trabalho e problemas de sucessão familiar.

Ostapechen (2019) realizou uma análise da produtividade de leite no Oeste paranaense, devido sua heterogeneidade, identificando que a orientação técnica para o aumento da produtividade e necessidade de um nível mínimo de escolaridade para o gestor da propriedade. $\mathrm{O}$ autor apontou que o produtor de leite precisa buscar por conhecimento para melhor gerenciar a atividade e aumentar a produtividade.

No contexto internacional, Kamath, Biju e Kamath (2019), analisaram o cenário indiano no intuito de identificar os vários problemas enfrentados pelos produtores de leite e outras partes interessadas na Índia rural. Evidenciando como dificuldades os preços elevados de combustíveis e suprimentos, falta de assessoria técnica especializada, mão de obra desqualificada e indisponibilidade de forragens para alimentação do rebanho. Apesar de os autores destacarem que a Índia é um dos maiores produtores de leite do mundo, a produção concentra-se em pequenos produtores, cerca de $62 \%$ da produção total, com uma representatividade $27 \%$ da renda familiar. Porém, há evidências de necessidade de capacitação dos produtores para o desenvolvimento da atividade e que o governo se propôs a criar programas de incentivos a pecuária leiteira.

Cravioti e Vértiz (2020) entrevistaram 45 produtores de leite argentinos em relação às perspectivas de continuidade e sucessão na atividade leiteira de pequenos estabelecimentos familiares. Identificando que muitos consideram parar com o desenvolvimento potencial da atividade leiteira motivados pelas dificuldades de condições de trabalho consideradas como satisfatórias para as pequenas propriedades com baixa produção, das limitações da atividade no cenário nacional que preconiza aumento da produção e produtividade.

A maioria das pesquisa apresentam resultados semelhantes, apontando que a atividade leiteira apresenta um papel importante de contexto social e econômico visto que as pequenas propriedades possuem dificuldades compreendidas desde a necessidade acompanhamento técnico, baixo preço de revenda do produto, disponibilidade de mão de obra, envelhecimento, problemas de sucessão familiar, necessidade de capacitação para a gestão além de políticas públicas que possam dar suporte para a continuidade da atividade.

Na sequência, são apresentados os procedimentos metodológicos que conduziram a realização do estudo, com base no instrumento de pesquisa de Freitas (2014), que foi aplicado com pequenos produtores de leite de um município do Sudoeste paranaense.

\section{PROCEDIMENTOS METODOLÓGICOS}

No intuito de atender ao objetivo proposto para a pesquisa de identificar as principais dificuldades enfrentadas pelos pequenos produtores de leite do município de Verê - PR, utilizou-se a pesquisa descritiva, por meio de levantamento e com abordagem qualitativa.

A aplicação do questionário deu-se em três das comunidades pertencentes ao município de Verê - PR, que é dividido em 28 comunidades na zona rural. Destas, foram selecionadas as três comunidades que possuíam maior quantidade produtores de leite no município, entrevistando-se os produtores das comunidades de Pitangueiras, Bananal e Águas do Verê. Ainda, foram selecionados de forma aleatória e por acessibilidade uma amostra de 25 produtores de leite. Sendo 3 pequenos produtores da comunidade de Pitangueiras, 13 produtores da comunidade de Águas do Verê e 9 produtores da comunidade de Bananal.

A coleta dos dados foi feita em visita in loco em cada uma das propriedade nos meses de junho a agosto de 
2018, fato este que propicia ao pesquisador uma melhor percepção para interpretação dos dados qualitativamente, o que não ocorre quando o questionário é enviado por outros meios.

O instrumento utilizado para a coleta de dados é um questionário adaptado do estudo de Freitas (2014), que realizou abordagem semelhante juntos aos pequenos produtores de leite do município do Cacoal - RO. Sendo composto por questões fechadas e abertas, dividido em três blocos: (I) Perfil dos respondentes; (II) Perfil das propriedades leiteiras e dificuldades enfrentadas e; (III) Políticas públicas de incentivo aos pequenos produtores de leite.

Em que o perfil socioeconômico dos pequenos produtores de leite é identificado com base nas questões do Bloco I, suas dificuldades no desenvolvimento da atividade de pecuária leiteira no Bloco II, bem como as políticas públicas disponíveis para fortalecer o desenvolvimento local e regional da atividade no Bloco III.

A análise dos dados obtidos será de forma qualitativa, no intuito de melhor descrever os resultados, sendo desenvolvida com base nos blocos que compõe o questionário. $\mathrm{O}$ conteúdo das respostas abertas foram interpretadas e relacionadas por semelhança de conteúdo e em seguida descritas as conclusões obtidas pelo pesquisador. Para as questões fechadas, os dados foram tabulados e expressos com uso de gráficos e tabelas. No intuito de facilitar a interpretação, a descrição dos resultados foi feita de forma descritiva para permitir melhor cotejamento com os estudos correlatos.

\section{RESULTADOS E DISCUSSÃO}

Nesta seção é apresentada a análise dos dados com base no questionário aplicado aos pequenos produtores de leite de três comunidades do município de Verê - PR. A sequência de análise será a mesma dos blocos de perguntas do questionário. A saber: (I) Perfil dos respondentes; (II) Perfil das propriedades leiteiras e dificuldades enfrentadas e; (III) Políticas públicas de incentivo aos pequenos produtores de leite.

\subsection{Perfil dos respondentes}

Com base nos dados relacionados ao perfil dos respondentes, encontra-se baixo índice de jovens desempenhando essa atividade, apenas 4\%, com idade entre 21 a 30 anos. Ainda, 16\% apresentam idade entre 31 a 40 anos, 44\% apresentam idade entre 41 a 50 anos e $36 \%$ apresentam mais de 51 anos. A maioria deles, cerca de $76 \%$ são casados. Na composição familiar, $12 \%$ não possuem filhos, $8 \%$ possuem apenas um filho, $64 \%$ possuem dois filhos e $16 \%$ possuem mais de dois filhos. Ou seja, fica evidenciado que a maioria dos casais possuem no máximo dois filhos, fato este que representa um possível problema de sucessão familiar (Freitas, 2014; Bánkuti et al., 2018; Arends-Kuenning et al., 2020; Breitenbach \& Rosolen, 2020), sendo acentuado quando o casal não possuí filhos do sexo masculino (Arends-Kuenning et al., 2020). Enfatizam Loose et al. (2019) que a migração de jovens para a cidade em busca de emprego demonstra a necessidade de implementação de políticas públicas para incentivar sua permanência ou retorno ao interior.

Quando questionados sobre o número de pessoas que residem nas propriedades dos pequenos produtores de leite, que na maioria dos casos é apenas a família, percebe-se diversidade nas respostas. Em que 4\% apresentaram uma pessoa residindo na propriedade, $24 \%$ apresentam duas pessoas, $28 \%$ apresentam três pessoas, $28 \%$ apresentam quatro pessoas e $16 \%$ apresentam mais do que quatro pessoas residindo na propriedade.

Partindo do pressuposto de uso de mão de obra familiar na atividade, evidencia-se que o casal permanece na zona rural, mas, os filhos migraram para cidade, seja para estudar ou porque optaram por não mais trabalhar na atividade rural. Fato semelhante evidenciado nas pesquisas de Freitas (2014), Bánkuti et al. (2018), ArendsKuenning et al. (2020) e Breitenbach e Rosolen (2020), que apontaram dificuldades relacionadas com a sucessão familiar, além de que existe o declínio de fertilidade e o envelhecimento da população do campo. Ou seja, há poucas pessoas residindo nas propriedades rurais, com idade mais avançada e as famílias estão tendo cada vez menos filhos. O jovens que residem nestas, acabam muitas vezes por terem oportunidades de trabalho e educacionais nas cidades, fator que afeta a sucessão familiar na atividades. Diante desta situação, de que apenas o casal permanence na atividade rural e com a saída dos filhos do seio familiar, a tendência é que cesse a atividade leiteira pelo avanço da idade e redução de mão de obra. $\mathrm{Na}$ sequência, são apresentados os resultados relacionados ao Bloco II - Perfil das propriedades leiteiras e dificuldades enfrentadas.

\subsection{Perfil das propriedades leiteiras e dificuldades enfrentadas}

Os respondentes se enquandram como pequenos produtores. Na maioria dos casos, cerca de $56 \%$, quem 
exerce e desenvolve a atividade leiteira, são duas pessoas, ou seja, o casal. Em $24 \%$ das propriedades tem uma pessoa trabalhando na atividade, em $16 \%$ tem três pessoas trabalhando e $4 \%$ tem quatro pessoas trabalhando. Nenhuma das propriedades tem funcionários trabalhando, todas utilizam de mão de obra familiar na atividade.

Uma questão relevante destes dados, está relacionado aos filhos envolvidos na atividade leiteira, como percebe-se, na maioria das propriedades a atividade leiteira é realizada pelo casal, pois alguns não têm filhos e os que têm, na maioria dos casos saíram de casa em busca de novas oportunidades de empregos ou para estudar. As demais propriedades que mencionaram ter mais de duas pessoas trabalhando na produção de leite, seria pelo fato de possuírem filhos menores, ou que residem ainda na casa de seus pais, dessa maneira auxiliam na atividade.

Em relação ao total das pessoas que residem na propriedade, identifica-se a dependência da renda proveniente da atividade leiteira. Sendo considerada como uma das principais rendas da propriedade, por ser recebida mensal propicia fluxo de caixa para pagamento das despesas familiares.

Fato posto que para a maioria dos respondentes, a atividade leiteira representa a principal fonte de renda, sendo que $68 \%$ das propriedades, consideram a atividade de grande importância como geradora de recursos financeiros. Em contrapartida, 32\% afirmaram que o leite não é a atividade principal, porém é um dos segmentos que auxiliam da renda, juntamento com a produção de grãos e outras atividades realizadas dentro ou fora da propriedade familiar. Esta combinação de atividades agrícolas e outras atividades monetárias, é conhecida como pluriatividade. Este fenômeno de combinação de atividades vem crescendo consideravelmente a partir dos anos de 1990 (Cruz, 2012).

Outro questionamento foi em relação a propriedade, em que foi possível apurar que das vinte e cinco famílias, oito utilizam toda a propriedade para a produção de leite, entre pastagem temporária e permanente, plantação de milho que servirá de alimento ao rebanho, entre outros. As demais propriedades, associam a produção leiteira com outros cultivos (milho, soja, fumo). Além disso, foi identificado que em cinco famílias há pelo menos um integrante que trabalha na iniciativa privada com carteira assinada, complementando a renda. Reforçando assim a existência de pluriatividade (Cruz, 2012) como uma forma de viabilizar a agricultura familiar no meio capitalista
(Telles et al., 2008) e corroborando com os resultados da pesquisa de Parré et al. (2011), de que nem todas as propriedades que desenvolvem a atividade leiteira, tem está como única atividade desenvolvida.

Em relação ao tempo em que as famílias estão desempenhando a produção de leite, percebeu-se que $56 \%$ das propriedades de pequeno porte trabalham há mais de vinte anos com a atividade. Sendo um trabalho que vem passando de geração para geração, que esteve presente na infância da maioria destas famílias e hoje elas dão continuidade ao segmento leiteiro em suas propriedades. Fato este que destoa em partes dos relatos de pesquisas como Freitas (2014), Bánkuti et al. (2018), Arends-Kuenning et al. (2020) e Breitenbach e Rosolen (2020), que trazem como principal dificuldade a questão da sucessão familiar na atividade, uma vez que até então a atividade foi passada de geração e geração. Porém, quanto a futura sucessão familiar desta geração, cabem estudos futuros.

O leite produzido em todas propriedades rurais, tem como destino a venda para laticínios da região. Em que $60 \%$ dos produtores vendem para laticínios situados no município de Verê-PR e 40\% dos produtores, por opção de preço e outros elementos avaliativos, vendem para laticínios localizados fora do município.

A ordenha do leite em vinte duas propriedades é feita de forma mecânica e em três ainda é realizado de forma manual. Em média, o valor pago pelo litro ao produtor fica em torno de $\mathrm{R} \$ 1,17$, alguns ganham um pouco mais no valor pago por litro em vista da quantidade produzida. Este valor é considerado por todos um preço baixo segundo os respondentes da pesquisa, considerando que não foram levantados dados relacionados aos custos e despesas que envolvem toda a atividade. Nos resultados de Freitas (2014) e Loose et al. (2019), uma das dificuldades apuradas está relacionada com o preço pago aos produtores pelo litro de leite. Fato também relacionado nas dificuldades apontadas pelos respondentes desta pesquisa. Na Figura 1, podese observar a quantidade de litros/leite que é produzida mensalmente nas propriedades estudadas.

Como se pode observar no Figura 1, a produção mensal de leite pelas famílias, na maioria dos casos, está abaixo dos 4.000 mil litros, sendo assim, é considerado uma produção de pequeno porte, pelo fato de estas famílias possuírem pouca área de terra e recursos financeiros para investir na propriedade para ampliar a produção leiteira. 


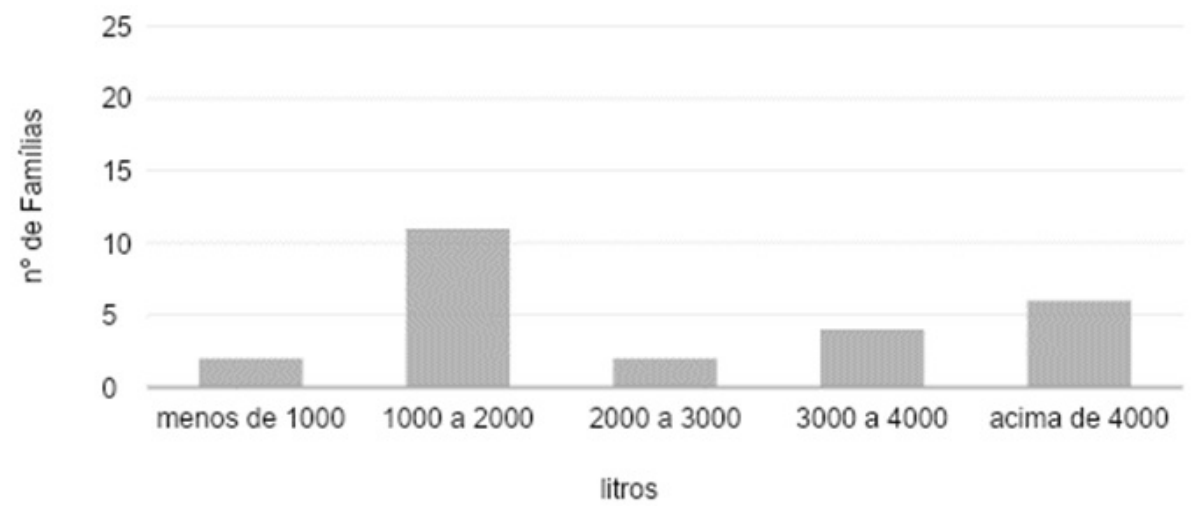

FIGURA 1 - Produção mensal de leite

Fonte: Dados da Pesquisa (2018)

Em contrapartida, as intenções futuras dos pequenos produtores variam entre as famílias respondentes. Das quais, $16 \%$ dos proprietários pretendem abandonar ou diminuir a produção, os motivos estão ligados ao preço baixo pago pelo litro, que gera pouco retorno e muitos custos relacionados a produção. Destacam de Sousa Costa et al. (2015) que os produtores precisam obter mais conhecimentos por meio de novas experiências que proporcionem alternativas mais eficazes e viáveis para o processo produtivo. Além disto, alguns produtores já estão com idade avançada, tendo intenções de se aposentar e consequentemente parar com a atividade leiteira.

Semelhante aos achados de Freitas (2014) que evidenciou como motivos para parar com a atividade leiteira a pouca disponibilidade de mão de obra, idade avançada e redução do tamanho das famílias. Também corroboram com estes resultados Breitenbach e Rosolen (2020) que identificaram como fraquezas do setor produtivo de leite margem de lucro baixa e dificuldades de sucessão familiar e como uma ameaça a instabilidade dos preços e custos. Ainda, dos demais respondentes, cerca de $24 \%$ pretendem aumentar a produção e $44 \%$ pretendem manter a produção atual.

Os produtores também relataram que recebem visitas técnicas de veterinários, sendo em todos os casos, quando solicitadas. Kamath et al. (2019) reforçam que há evidências de necessidade de capacitação dos produtores para o desenvolvimento da atividade. Entretanto, alguns produtores pagam por essa assistência técnica, outros possuem convênios e afirmaram que não pagam, enquanto outros são assistidos, mediante solicitação, a assistência técnica de veterinários da Prefeitura
Municipal do município, que pode ser gratuita com cobrança de insumos utilizados. Destaca Ostapechen (2019), que a orientação técnica é importante, pois reflete em melhor gerenciamento da propriedade e aumento de produtividade.

E, também está associada a maiores níveis de produtividade (Parré et al., 2011). Em contrapartida, alguns produtores não recebem visitas técnicas, pois tentam resolver os problemas de seu rebanho por meio de medicamentos e informações resultantes de lojas veterinárias.

Outra questão levantada na pesquisa foi a realização de financiamentos ou investimentos com recursos de terceiros para melhorar a produção. Uma vez que o acesso ao crédito possibilita o fortalecimento das transações econômicas dos pequenos produtores, estimula novos investimentos e aumenta a geração de renda (LOOSE et al., 2019). Os resultados apontam que $60 \%$ dos pequenos produtores fizeram financiamentos para progredir na produção leiteira, investindo na compra de ordenhadeiras e outros equipamentos. Também, investiram na construção e reforma de estrebarias, compra de rebanhos e melhoramento de pastagem. Parré et al. (2011) associam que maiores níveis de produtividade ao nível tecnológico, uso de mecanismos de gestão, tempo na atividade leiteira, tamanho de área e acesso a recursos. Podendo estar associadas a programas de acesso ao crédito para investimentos e melhorias. Já, para $40 \%$ dos respondentes, indicaram que não realizaram nenhum tipo de financiamento ou investimentos com recursos de terceiros voltados a produção, utilizando recursos próprios para investir na área. 


\subsection{Políticas públicas de incentivo aos pequenos produtores de leite}

No município de Verê - PR, existem ações e projetos que visam estimular e apoiar os pequenos produtores na produção leiteira, que são coordenados por entidades e por órgãos públicos, como por exemplo a própria Prefeitura Municipal de Verê. Como: Programa Saúde Animal; Programa Melhoramento Genético em Bovinos; Curso de Capacitação sobre Vacas Leiteiras; Leite Sudoeste; Obra de Cascalhamento; PGPAF e; Pronaf.

Estas políticas públicas desenvolvidas e ofertadas aos pequenos produtores são de suma importância para os mesmos, como evidenciado em pesquisa de Telles et al. (2008), que associam a viabilidade da agricultura familiar com ênfase na necessidade de políticas públicas, uma vez que estas são importantes para a manutenção das pequenas propriedades e incentivam o desenvolvimento da pecuária leiteira (Kamath et al., 2019).

Quando questionados sobre acesso às políticas públicas, $84 \%$ dos entrevistados afirmaram que têm conhecimento sobre alguns programas e ações oferecidas a eles por meio da administração municipal e por cooperativas localizadas no município. Dentre elas, os produtores destacaram o programa de Melhoramento Genético em Bovinos (Inseminação) e o Pronaf, que por meio deste, as famílias contraem o financiamento com o intuito de melhoramento de condições para desenvolver sua atividade.

Afirmaram ter conhecimento também sobre o projeto de Cascalhamento, que tem como objetivo a melhoria das estradas que dão acesso as estrebarias dos produtores de leite. Reinteram Parré et al. (2011) e Loose et al. (2019) que algumas dificuldades enfrentadas pelas agricultura familiar relacionadas a produção de leite são acesso ao crédito, dificuldades de malha viária para escoamento da produção e falta de assistência técnica especializada, que podem ser resolvidas mediante a implantação de políticas públicas. No entanto, observouse que $16 \%$ não têm conhecimentos sobre algum tipo de programa ou ação que beneficiam e auxiliam a sua produção. O conhecimento sobre programas e ações voltados aos produtores rurais é primordial para que estes possam acessá-los, sendo que a falta de informação e conhecimento sobre estes é considerado como um agravante da situação deles (Freitas, 2014).

Destes produtores que afirmaram ter conhecimento sobre as políticas públicas, cerca de $80 \%$ deles já foram e são beneficiados atualmente por programas e ações disponibilizados aos mesmos. Sendo que os programas mais acessados são o Pronaf e o programa de Inseminação. $\mathrm{O}$ acesso a políticas públicas possibilita o fortalecimento dos pequenos produtores, principalmente os pertencentes a agricultura familiar (Telles et al., 2008).

Já para o projeto de Cascalhamento muitos produtores se cadastraram, mas ainda não foram atendidos pela administração pública. Os demais, 20\% dos produtores não são beneficiados pelos programas. Percentual inferior aos resultados de Vargas et al. (2017) de $48,5 \%$ dos respondentes e $43,3 \%$ na pesquisa de Loose et al. (2019), em que os produtores rurais não buscavam por acesso a crédito, principalmente na modalidade de Pronaf, justificando que não se enquadrariam ou incapacidade de pagamento. Destaca Freitas (2014) que as instituiçoes crédito tendem a liberar valores menores para os pequenos produtores, face a estes terem propriedades de pequeno porte, que pode vir a impossibilitar melhorias na propriedade e consequentemente refletir na produção.

A atividade leiteira, além de ser uma das principais fontes de renda da propriedade e fonte de alimento para a população, também apresenta alguns problemas e dificuldades para seu desenvolvimento. Em que para todos os produtores entrevistados evidenciaram que a variação e preço pago pelo litro de leite, gera instabilidade de renda podendo se tornar um contundente empecilho para a continuidade da atividade. Outra dificuldade apontada pelos respondentes relaciona-se com a idade avançada de alguns produtores, pois o trabalho se torna pesado e cansativo quando há pouca mão de obra. Relatam também dificuldades relacionadas a sucessão familiar em decorrência do número reduzido de filhos e a migração destes para a cidade em busca de emprego.

Ainda, outro fator que gera dificuldades para os produtores de leite é o investimento em novas tecnologias e melhoramento da sua produção, pelo fato de apresentarem propriedades pequenas e sem muitos recursos. Apontando a necessidade de mais incentivos por meio de políticas públicas aos pequenos produtores de leite que promovam novas oportunidades no segmento da produção.

Por fim, analisando os resultados da pesquisa pode-se perceber resultados semelhantes as pesquisas realizadas por Telles et al. (2008), Parré et al. (2011), Freitas (2014), Bánkuti et al. (2018), Kamath et al. (2019), Loose et al. (2019), Arends-Kuenning et al. (2020) e Breitenbach e Rosolen (2020), que apontaram, dentre outras dificuldades enfrentadas pelos pequenos produtores, dificuldades relacionadas com o preço do litro de leite, idade avançada, sucessão familiar, número reduzido de 
filhos e investimento em novas tecnologias. Reforçando que todos citam as que a implementação de políticas públicas favorecem e fortalecem a atividade leiteira nas pequenas propriedades.

\section{CONSIDERAÇÕES FINAIS}

A pecuária leiteira, além de enfrentar problemas, é uma atividade com um potencial significativo para as comunidades de Bananal, Linha Pitangueiras e Águas do Verê, e ao mesmo tempo para o Município de Verê - PR, auxiliando no desenvolvimento da economia da cidade e contribuindo para o fomento dos pequenos produtores.

O leite é um produto alimentício importante para muitos, sendo utilizado para produção de outros produtos presentes na mesa dos consumidores. Percebe-se, que a produção de leite é desenvolvida em grande parte por pequenos produtores, que desempenham a função por meio da mão de obra predominantemente familiar, tornando-se em muitos casos sua principal fonte de renda e o sustento de sua família.

Tendo em vista a importância da atividade para muitos desses pequenos produtores envolvidos é preciso considerar que eles enfrentam dificuldades para desempenharem a atividade. Dentre as elencadas, a principal dificuldade enfrentada foi o valor que recebem pelo litro de leite produzido, uma vez que este é instável e representa um desafio para o equilíbrio entre receitas e depesas. Além desta dificuldade, foram apontadas a idade avançada, sucessão familiar, número reduzido de filhos e investimento em novas tecnologias.

Neste sentido, visualiza-se um cenário em que a atividade leiteira desenvolvida em pequenas propriedades tende com o tempo a ser descontinuada, caso não sejam implementadas políticas públicas de incentivo e que tragam benefícios aos pequenos produtores no desempenho desta atividade. Considerando que mesmo havendo disponibilidades, ainda não são suficientes para atender aos anseios e necessidades destes pequenos produtores.

Ainda, se faz necessário pontuar que os produtores precisam fazer investimentos relacionados a melhorias no processo produtivo, necessitando de um orçamento planejado e adequado. Porém, falta-lhes mais incentivos e apoio dos órgãos administrativos, para que os produtores consigam se manter e até aumentar a atividade em suas pequenas propriedades. A intensificação de mais políticas públicas e de créditos mais acessíveis aos produtores é de fundamental importância.
Partindo deste pressuposto, os produtores conseguiriam investir em melhorias, buscando crescimento individual e a manutenção dos seus filhos na atividade, já que muitos saem em busca de melhores condições e oportunidades. Conclui-se, que é preciso o estabelecimento de um planejamento governamental, visando fortalecer a atividade e possibilitando a permanecia e continuidade da mesma nas pequenas propriedades. Dessa forma, os produtores não necessitam abandonar essa atividade tão importante para a economia e para as inúmeras famílias que dependem dos recursos oriundo dela.

Como limitação do estudo elenca-se a amostra utilizada no estudo, pois foram produtores do município do Verê-PR. Sugere-se para estudos futuros a ampliação da amostra e estudo de viabilidade do desenvolvimento da atividade em detrimento a outra atividade.

\section{CONFLITO DE INTERESSES}

Não houve conflitos de interesse no assunto ou nos materiais discutidos neste manuscrito.

\section{REFERÊNCIAS}

AGÊNCIA DE NOTÍCIAS DO PARANÁ. Paraná é o segundo maior produtor de leite do País. 2016. Disponível em: <http://www.aen.pr.gov.br/modules/ noticias/article.php?storyid $=91046 \&$ tit $=$ Parana-e-osegundo-maior-produtor-de-leite-do-Pais $>$. Acesso em: 02 de jun. de 2018.

Arends-Kuenning, M., Kamei, A., Garcias, M., Romani, G. E., \& Shikida, P. (2020). Gender, Education, and Farm Succession in Western Paraná State, Brazil.

Bianchini, V. (2015). Vinte anos do PRONAF, 1995-2015: avanços e desafios. Brasília: SAF/MDA, 45-68.

Bánkuti, F. I., Damasceno, J. C., Schiavi, S. M., Kuwaraha, K. C., \& Prizon, R. C. (2018). Structural features, labor conditions and family succession in dairy production systems in Paraná State, Brazil. Cahiers Agricultures, 27(4), 45004.

Breitenbach, R., \& Rosolen, G. B. (2020). Análise estratégica do setor produtivo de leite do Rio Grande do Sul. Revista de Política Agrícola, 29(4), 83. Recuperado de https://seer.sede.embrapa.br/index.php/RPA/article/ view/1545/pdf 
Carvalho, G. R. (2017). Mudanças da produção leiteira na geografia brasileira: o avanço do Sul. Agropecuária Catarinense, 30(2), 13-16.

Carvalho, J. L. A. S. (2013). Análise da sustentabilidade da atividade bovina leiteira no Município de Pombal. (Dissertação de Mestrado Profissional), Programa de Pós-graduação em Sistemas Agroindustriais, Centro de Ciências e Tecnologia Agroalimentar, Universidade Federal de Campina Grande - Pombal - Paraíba Brasil.

Craviotti, C., \& Vértiz, P. (2020). Traspaso trunco: la continuidad de los productores lecheros familiares en cuestión. Eutopía. Revista de Desarrollo Económico Territorial, (18), 119-136.

de Sousa Costa, V., de Albuquerque Assunção, A. B., da Costa, M. M. B., \& Chacon, M. J. M. (2015). Análise de custos a partir da cadeia do valor do leite e seus derivados na região Seridó do Rio Grande do Norte. Revista ambiente contábil, 7(1), 89-108.

Cruz, S. S. D. (2012). O fenômeno da pluriatividade no meio rural: atividade agrícola de base familiar. Serviço Social \& Sociedade, (110), 241-269.

FAO. Food and Agriculture Organization of the United Nations. (2021). Gateway to dairy production and products: Milk and milk products. Disponível em: < http:// www.fao.org/dairy-production-products/products/en/ $\geq$. Acesso em: 16 de mar. de 2021.

Freitas, R. T. (2014). Dificuldades enfrentadas pelos produtores de leite da linha 3 do município de CacoalRO. p. 41.

Grisa, C., \& Schneider, S. (2014). Três gerações de políticas públicas para a agricultura familiar e formas de interação entre sociedade e estado no Brasil. Revista de economia e sociologia rural, 52, 125-146.

IBGE. Instituto Brasileiro de Geografia e Estatística. (2009). Agricultura familiar ocupava 84,4\% dos estabelecimentos agropecuários. Disponível em: < https:// agenciadenoticias.ibge.gov.br/2013-agencia-de-noticias/ releases/13721-asi-agricultura-familiar-ocupava-844dos-estabelecimentos-agropecuarios.html >. Acesso em: 18 de jun. de 2018.
IBGE. Instituto Brasileiro de Geografia e Estatística. (2015). Produção da Pecuária Municipal. vol. 43. Rio de Janeiro. Disponível em: <https://biblioteca.ibge.gov. $\mathrm{br} / \mathrm{visualizacao} / \mathrm{periodicos} / 84 / \mathrm{ppm}$ 2015_v43_br.pdf $>$. Acesso em: 02 de junho de 2018.

IBGE. Instituto Brasileiro de Geografia e Estatística. (2017). Pecuária. Disponível em: < https://cidades.ibge. gov.br/brasil/pr/vere/pesquisa/18/16459>. Acesso em: 10 de junho de 2018.

IBGE. Instituto Brasileiro de Geografia e Estatística. (2015). PPM 2014: Rebanho Bovino Alcança 212,3 milhões de cabeças. Disponível em: < https://agenciadenoticias.ibge. gov.br/agencia-sala-de-imprensa/2013-agencia-de-noticias/ releases/10086-ppm-2014-rebanho-bovino-alcanca-212-3milhoes-de-cabecas.html > . Acesso em: 29 de mai. de 2018.

Júnior, A. A. M., \& Jung, C. F. (2017). Produção leiteira no Brasil e características da bovinocultura leiteira no Rio Grande do Sul. Ágora, 19(1), 34-47.

Kamath, V., Biju, S., \& Kamath, G. B. (2019). A Participatory Systems Mapping (PSM) based approach towards analysis of business sustainability of rural Indian milk dairies. Cogent Economics \& Finance, 7(1), 1622172.

Kuhn, S. L., \& Junior, D. J. R. (2015). O crédito rural na agricultura familiar, da mesorregião Oeste do Paraná, Brasil. Ciências Sociais Aplicadas em Revista, 15(28), 128-150.

Loose, C. E., Sandri, E. A., Simões, M. T., Piacentini, A. L. S. P., \& Cristina, P. Difficulties Facing Family Agriculture in Cacoal City, Rondônia/Brazil. International Journal of Advanced Engineering Research and Science (IJAERS), 6 (9), 202-210.

MAPA. Ministério da Agricultura, Pecuária e Abastecimento. (2015). Projeções do Agronegócio Brasil 2014/15 a 2024/25: Projeções de Longo Prazo. 6 ed. Brasília - DF. Disponível em: <http://www.brasilagro. com.br/imagens/projecoes_do_agronegocio_2025_webok.pdf>. Acesso em: 29 de maio de 2018.

Mendonça, B. S. D., Bánkuti, F. I., Pozza, M. S. D. S., Perez, H. L., \& Siqueira, T. T. D. S. (2020). A typology of corporate and family dairy farms in eastern Goiás, Brazil. Ciência Rural, 50(10). 
Ostapechen, L. A. P. (2019). Análise dos Determinantes da Produtividade Leiteira Municipal na Mesorregião Oeste do Paraná. Revista Paranaense De Desenvolvimento, 40(137), 13-27.

Parré, J. L., Bánkuti, S. M. S., \& Zanmaria, N. A. (2011). Perfil socioeconômico de produtores de leite da região Sudoeste do Paraná: um estudo a partir de diferentes níveis de produtividade. Revista de Economia e Agronegócio, 9(2).

Porto, M. (2017). O marketing de relacionamento na cadeia produtiva do leite: um olhar sob a ótica reversa.

SEAB. Secretaria de Estado da Agricultura e do Abastecimento. DERAL. Departamento de Economia Rural. (2017). Estado do Paraná. Secretaria da Agricultura e do Abastecimento. Departamento de Economia Rural. Conjuntura agropecuária safra 2016/17. Março. Disponível em: < http://www.agricultura.pr.gov.br/ arquivos/File/deral/Prognosticos/2017/leite_2016_17. pdf_>. Acesso em: 24 de jul. de 2019.
Telles, T. S., Tanaka, J. M. U., \& Pellini, T. (2008). Agricultura familiar: pecuária leiteira como locus das políticas públicas paranaenses. Semina: Ciências Agrárias, 29(3), 579-590.

Vargas, D. L.; Ferreira, A. G.; Godoy, C. M. T.; \& Guedes, A. C. (2017). PRONAF e agricultura familiar: o contexto do município de cachoeira do sul, RS. $X$ Seminário Internacional sobre Desenvolvimento Regional.

Zoccal, R. (2017). A Força do Agro e do Leite no Brasil. Revista Balde Branco. São Paulo. Disponível em: <http:// www.baldebranco.com.br/forca-agro-e-leite-no-brasil/>. Acesso em: 29 de mai. de 2018.

Zoccal, R. (2017). Paraná um estado cada vez mais leiteiro. Revista Balde Branco. São Paulo. 2017. Disponível em: $<$ http://www.baldebranco.com.br/paranaum-estado-cada-vez-mais-leiteiro/>. Acesso em: 02 de jun. de 2018.

Organizações Rurais \& Agroindustriais, Lavras, 23:e1647, 2021 